\title{
SÁ, Guilherme. No mesmo galho: antropologia de coletivos humanos e animais. Rio de Janeiro: 7Letras, 2013. 224 p.*
}

\author{
Victor Abreu Amante** \\ Universidade Estadual de Campinas - Brasil
}

No mesmo galho: antropologia de coletivos humanos e animais foi publicado em 2013 como resultado de uma tese de doutorado de 2006, levada a cabo pelo antropólogo Guilherme Sá no Programa de Pós-Graduação de Antropologia Social da Universidade Federal do Rio de Janeiro. Algumas referências do debate teórico e acadêmico da antropologia contemporânea são citadas, dentre as quais poderíamos mencionar a discussão da validez antropológica dos polos natureza e cultura, assim dicotomizados, e aqueles empreendidos por Eduardo Viveiros de Castro e Bruno Latour. Assim, já de antemão somos situados dentro do tipo de pesquisa preconizada por Latour, que envolveria, principalmente, o "estudo social das ciências", isto é, a antropologia sobre o próprio Ocidente e, ainda mais, sobre sua própria produção científica.

A pesquisa tem lugar entre um grupo específico de primatólogos de Minas Gerais, participantes de diversos grupos de pesquisa que envolvem os muriquis da região, uma espécie de primata que se situa entre o macaco-prego e os babuínos. Poderíamos nos restringir aqui às personagens humanas observadas por Guilherme, mas, pelo próprio espírito da pesquisa, sabemos que fazer isso seria contar somente metade da história: os próprios coletivos não humanos ganham significância como agentes que afetam a pesquisa antropológica, de um lado, e a pesquisa científica dos primatólogos, de outro. Assim, deixá-los de lado seria ignorar sua importância enquanto sujeitos-objetos, e é esta conduta que o próprio autor irá priorizar: entender as relações intersubjetivas também entre humanos e não humanos, isto é, entre pesquisadores e

\footnotetext{
* Esta presente resenha não poderia ter sido realizada ou publicada sem o auxílio do professor Rodrigo Toniol, cujo incentivo e revisão foram essenciais para encontrarmos este texto em seu atual conteúdo e formato. Por esses motivos, quero deixar aqui registrado meu agradecimento.

** Graduando em Ciências Sociais. Contato: victoramante95@hotmail.com
} 
muriquis, ou ainda, dentro dos coletivos humano e não humano. (Aliás, essa é uma das constantes na pesquisa de Sá na medida em que até o processo de nomeação e identificação dos muriquis será entendido na chave da mutualidade.)

O antropólogo define, durante o livro, alguns eventos centrais que conduzem a pesquisa, demarcando assim a importância dos mesmos para o desenrolar da etnografia, o que nos diz muito sobre esse processo descontinuado que é a escrita e a observação participante. E não só os eventos, mas também algumas figuras humanas adquirem relevância nesse contexto, tal como Jonas, um dos chefes de equipe.

Algumas dificuldades revelarão uma preocupação fundamental desses cientistas primatólogos que tangencia também a pesquisa etnográfica: outro pesquisador na área poderia significar nem tanto um problema para os pesquisadores dos primatas, mas antes um problema para os primatas dos pesquisadores. A pressuposição básica para aqueles biólogos era de que os primatas, ainda que sabendo ser observados, poderiam performar naturalmente em seu hábitat natural, sem qualquer intervenção significativa. A entrada do antropólogo em campo poderia significar um desequilíbrio dessa relação "objetiva", não obstante os próprios primatólogos saibam que os primatas sabem que estão sendo observados quando de fato o estão. Isso significa, dirá o autor (p. 31), que mesmo sendo o caso de uma ciência objetiva da natureza, os pesquisadores estão refletindo sobre si mesmos quando atribuem personalidades aos macacos, tal como se esperaria somente das ciências humanas. E não diferentemente o antropólogo aqui sabe que os "nativos" que pesquisa também o traduzem de acordo com suas experiências mútuas, seja como etnógrafo, seja como pesquisador ou "visitante".

O primeiro momento de pesquisa de Guilherme Sá na Estação Biológica de Caratinga inicia em 2002, prolonga-se em 2003 e se torna pontual em 2004. $\mathrm{O}$ autor explicita que se trata de uma pesquisa parcial e de um tempo vivido específico, impossível de dar conta da totalidade potencial de um estudo dedicado a primatólogos e primatas.

O livro segue com a descrição etnográfica do trabalho de campo dos primatólogos. São-nos narrados seus horários, suas vestimentas e equipamentos e suas interações humanas e não humanas: a vida na mata passará por um processo de laboratorialização.

Outro tópico trata da imagem construída sobre os muriquis, no que tange à sua identidade relacional (aos fazendeiros, biólogos, etc.) e seu "modelo" de 
comportamento. As primeiras passagens narram a transição da imagem dos primatas em questão de seres violentos e agressivos para seres pacíficos e curiosos. Esse processo se deu principalmente com a vinda dos primatólogos e com o evento do "abraço do mono" (antes entendido, inclusive por pesquisadores, como um "comportamento de intimidação"): foi com a releitura desse abraço que se deslocou a imagem social dos muriquis. De intimidação e confronto ao homem - caçador - à demonstração de afeto e de unidade - aos semelhantes -, o abraço primata passa por uma releitura do coletivo muriqui, antes ameaçado pelo ser humano e, agora, "devidamente" estudado, acompanhado e preservado, compondo uma sociedade pacífica não-hierarquizada. São por essas linhas que a identidade social dos muriquis chega ao "macaco hippie", o qual, nessa condição, não obstante primata, tem mais a nos ensinar como seres humanos do que nós mesmos.

É por isso que, em acordo com Bruno Latour, Guilherme Sá nos dirá que são os próprios primatas - muriquis, no caso - os principais reformadores da visão que temos sobre os primatas (antes, no caso, os babuínos belicosos): a principal contribuição do primatólogo (ou, em termos gerais, do homem) é "dar a oportunidade de se comportar", é observar e tornar público seu sujeito-objeto para que ele mesmo, então, aja sobre sua imagem circulante; o observador não o está inventando, apenas permitindo que ele se invente.

Pensando sobre a identidade bilateral (mútua) dos muriquis, Guilherme Sá nos demonstra dois importantes pontos que disso decorrem: 1) que a nomeação se dá em função de memórias e experiências pessoais do pesquisador; 2) que se nomeia num contexto intersubjetivo, em que observador e observado são termos relacionais, e nunca objetivos - a percepção de determinados comportamentos ocorre num contexto humano versus não humano.

Se a nomeação é o primeiro passo para a individualização do macaco, significa que nomeá-lo é, portanto, o primeiro passo no estabelecimento da relação entre primatólogo e espécie. Neste campo o autor fará a diferenciação entre intersubjetividade e projeção, cuja divisão podemos rapidamente marcar através da noção de sujeito, plural na primeira e singular na segunda, e da noção de passividade, ausente na primeira: assim, não é o homem que se projeta sobre o macaco e o subjetiva, nomeando-o, mas ambos que, percebendo uns aos outros, interagem entre si, originando uma nomeação bilateral que possui sentido. Assim, "muriquis e primatólogos perpetuam-se sobrepondo suas experiências mutuamente" (p. 131). É também com o nascimento de um novo 
mono-carvoeiro que se permite ao primatólogo encarregado de nomeá-lo deixar seus vestígios humanos num corpo não humano.

Em determinado momento da obra, Guilherme Sá tensiona uma comparação lógica entre o movimento fenomenológico do perspectivismo ameríndio (cuja cosmologia é multinaturalista, em oposição à ocidental) e a intersubjetividade entre primatólogo e muriqui (isto é, teoricamente dada no regime multiculturalista ocidental). Temos, portanto, que mesmo no contexto científico percebem-se os primatas como observadores tais qual o homem, não obstante nem sempre reconheçam o (nosso) humano enquanto tal: assim sendo, narrativas científicas discorrem a favor da concepção de que os macacos teriam sua própria história e mitologia. Igualmente a Viveiros de Castro, o nosso autor confirmará que o cientista desempenha o mesmo papel que o xamã nas sociedades ameríndias, ambos seres híbridos, capazes de transitar entre o mundo humano e não humano, cujas fronteiras eles mediam.

Um dos capítulos, "Histórias de primos (equi)distantes", findará com a explanação do conceito de "predação científica". Esse conceito sugere que a passagem purificadora de sujeito para objeto, ideias para sujeitos, etc., está ligada a um tipo de lógica da predação: apoderar-se desse outro, por via do conhecimento, tem como condição "níveis seguros de alteridade", isto é, só se preda aquilo que é diferente de $E u$, da mesma maneira que o conhecimento transforma um sujeito em potencial num outro de direito, passando de uma relação de reconhecimento para outra de conhecimento.

$\mathrm{O}$ autor deixa-nos claro que nem tudo que é observado relata-se numa pesquisa científica, isso significa, de outro lado, que nem toda relação intersubjetiva aparece como predação científica; isso porque, novamente, no caso da predação científica existe uma passagem de percepção intersubjetiva para dado objetivo. Para predar o comportamento muriqui, era necessário reconhecê-lo, transformá-lo em número, o que nem sempre acontece.

Guilherme Sá reconhece, nas páginas do último capítulo, o "avanço" da primatologia que culturaliza seus sujeitos-objetos: se antes as espécies primatas eram vistas como estágios evolutivos anteriores do ser humano, como "proto-hominídeos", agora vemos a possibilidade de surgimento de seres híbridos, que estão entre os seres naturais e os seres culturalizados (humanos). Entretanto a crítica subsiste, visto que, argumenta nosso autor, devemos ser capazes de pensar os primatas em função de seu próprio universo, e não como seres dotados de uma cultura humana, da qual não escapam agora no "plano" 
das ferramentas e códigos. Sem antropomorfismo e sem órgãos homólogos, essa deve ser a "cultura primata". Evocando o argumento de Viveiros de Castro, resta que os animais são seres sociais e, por isso, sempre foram seres culturais, na medida em que estão uns em relação aos outros.

$\mathrm{Na}$ conclusão final do capítulo e, por conseguinte, do livro consta que são justamente os naturalistas que, em oposição à síntese via natureza dos humanos com não humanos, sintetizam via cultura os humanos e primatas: "sendo primatas somos todos nativos" (p. 192).

Assim sendo, poderíamos situar a pesquisa de Guilherme no contexto brasileiro: o que ele traz para as antropologias que atravessam o contexto de produção nacional? De certa maneira, a antropologia aqui perpetrada se situa "para fora" e "para dentro". Para fora porque se situa nos moldes de um tipo de pesquisa euro-americano, a antropologia da ciência latouriana. Para dentro porque seu contexto provém de realidades empíricas e relacionais de um contexto nacional, o Brasil. Desse modo, seu caráter duplo, mas nem por isso ambíguo, relata-nos uma antropologia de sobreposições: num certo sentido tradicional, porque é essa a dinâmica das pesquisas cientificas no Brasil (o dentro e o fora, o europeu e o brasileiro, o universal e o contingente), e num certo sentido nova, de correlações teóricas entre matrizes nacionais (perspectivismo, por exemplo) e estrangeiras (totemismo lévi-straussiano, de outro lado).

Temos então que, entretanto e no limite, curiosamente nosso autor não escapa de uma certa familiaridade clássica de seu objeto para com aquele tradicional da antropologia: o indígena. Através de uma citação de Lévi-Strauss, podemos pensar até que ponto, de fato e de direito, esse sujeito-objeto que são os primatólogos (e os primatas) realmente se diferenciam, num contexto etnográfico, daqueles interlocutores convencionais da antropologia:

A extrema familiaridade com o meio biológico, a atenção apaixonante que lhe dedicam, os conhecimentos exatos ligados a ele frequentemente impressionaram os pesquisadores como indicadores de atitudes e preocupações que diferenciam os indígenas de seus visitantes brancos. (Lévi-Strauss, 2008, p. 20).

$\mathrm{O}$ argumento aqui defendido se resume em que, se substituíssemos "indígenas" por "primatólogos" e "visitantes brancos" por "visitantes" apenas, ou "antropólogos", ainda obteríamos um texto fiel às relações reais entre esses sujeitos. Trata-se, vale dizer, menos de uma correspondência real entre 
indígenas e primatólogos e suas capacidades, e mais de uma comparação que evidencia a possibilidade inerente à antropologia de produzir contextos e objetos aproximados apesar de seu afastamento real, isto é, sua capacidade de colocar relações análogas entre situações sujeito-objeto ou autor-interlocutor distintas.

Portanto, seríamos levados a pensar o que produziu essa contiguidade contextual entre os primatólogos de Guilherme Sá e os indígenas de LéviStrauss, senão uma própria condição do fazer antropológico. Ora, a resposta está no próprio texto de Sá: seu exercício de se aproximar dos primatólogos numa posição ao mesmo tempo distanciada (a observação participante ambígua de Favret-Saada), para além da própria capacidade das diferenças empíricas, produz epistemologias e ontologias insuperáveis que fundamentam elas mesmas a necessidade de sua pesquisa, isto é, elas mesmas fornecem a diferenciação interessante para uma antropologia desses sujeitos-objetos.

\section{Referência}

LÉVI-STRAUSS, C. O pensamento selvagem. 8. ed. Campinas: Papirus, 2008. 